\title{
PENERAPAN MODEL PEMBELAJARAN KOOPERATIF TIPE GROUP INVESTIGATION TERHADAP KEMAMPUAN BERPIKIR KRITIS DAN HASIL BELAJAR SISWA PADA MATERI HIDROKARBON
}

\section{The Implementation of Cooperative Learning Models Group Investigation \\ Type towards The Ability of Critical Thinking and Students Learning Outcomes in Hydrocarbon Materials}

\section{Mahda Agustina Liani*, Yudha Irhasyuarna, Abdul Hamid}

Program Studi Pendidikan Kimia FKIP Universitas Lambung Mangkurat,

Jl. Brigjend. H. Hasan Basry Banjarmasin 70123 Kalimantan Selatan Indonesia *email: mahdaaliani@gmail.com

\begin{abstract}
Abstrak. Penelitian ini dilakukan untuk mengalalisis metode pembelajaran yang tepat pada materi Hidrokarbon siswa kelas X di SMAN 1 Sungai Tabuk tentang penerapan pola pembelajaran kooperatif tipe Group Investigation terkait dengan kemampuan berpikir kritis dan hasil belajar siswa. Tujuan dilakukannya penelitian ini adalah: (1) untuk mengetahui ada atau tidaknya perbedaan kemampuan siswa dalam berpikir kritis saat belajar dengan menggunakan pola pembelajaran kooperatif tipe Group Investigation dan siswa belajar hanya dengan menggunakan cara konvensional, (2) untuk mengetahi hasil belajar siswa yang telah menggunakan model pembelajaran kooperatif tipe Group Investigation dan pada siswa yang belajar hanya dengan pembelajaran model konvensional. Teknik pengumpulan data menggunakan teknik tes. Teknik analisis data pada penelitian ini menggunakan uji-t dengan analisis N-gain. Berdasarkan hasil dari penelitian ini didapatka kesimpulan (1) adanya perbedaan pada kemampuan berpikir kritis siswa secara signifikan dengan yang belajar menggunakan model pembelajaran kooperatif tipe Group Investigation dengan siswa yang belajar menggunakan metode pembelajaran konvensional, (2) adanya perbedaan antara hasil belajar siswa yang belajar dengan menggunakan model pembelajaran kooperatif tipe Group Investigation dengan siswa yang belajar menggunakan model konvensional.
\end{abstract}

Kata kunci: pembelajaran kooperatif, Group Investigation, kemampuan berpikir kritis, hasil belajar siswa.

\begin{abstract}
This study is conducted to analyze the appropriate learning method in Hydrocarbon material for Grade 10 students of SMAN 1 Sungai Tabuk about the application oflcooperative learning pattern in Group Investigation type related to critical thinking skill and student learning outcome. The objective of this study is: (1) to determine whether or not there are differences in students' ability to think critically in using cooperative learning pattern in of Group Investigation type and students learning by using conventional method only, (2) to find out the learning outcome of students who have implemented cooperative learning model in Group Investigation type and students who study only with conventional learning model. The data collection technique applies test techniques. The data analysis technique of this study applies the t-test with $N$ gain analysis. Based on the results of this study, it is concluded that (1) there is significant difference in students' critical thinking skill between those who learn by using cooperative learning model in Group Investigation type and students who learn by using conventional learning method and (2) there is difference in the learning outcomes between students who learn by using cooperative
\end{abstract}

Copyright $\odot$ JCAE-Jurnal Tugas Akhir Mahasiswa, e-ISSN 2613-9782

Program Studi Pendidikan Kimia FKIP Universitas Lambung Mangkurat 
learning model in Group Investigation type and students who learn by using conventional model.

Keywords: cooperative learning, group investigation, critical thinking skill, student learning outcome

\section{PENDAHULUAN}

Bidang studi kimia adalah satu dari berbagai macam bidang studi yang mempunyai keistimewaan tersendiri serta membutuhkan keahlian untuk menyelesaikan permasalahan yang berkaitan dengan teori, konsep, hukum, dan fakta yang ada dalam ilmu kimia. Bidang studi kimia merupakan pelajaran yang bertujuan untuk menemukan jawaban atas permasalahan mengenai apa, mengapa, dan bagaimana. Siswa secara aktif diharapkan dapat mencari sendiri konsep yang ada pada pelajaran kimia.

Masalah utama yang terjadi dalam pengajaran pada pendidikan resmi sekarang yakni masih kurangnya daya tarik murid-murid yang disebabkan oleh proses pengajaran yang bersifat konvensional, pada kegiatan belajar mengajar ini keadaan kelas cenderung teacher-centered atau guru sebagai pusat pembelajaran sehingga menyebabkan siswa menjadi kurang aktif (Depdiknas, 2003). Berdasarkan pengamatan awal pada mata pelajaran kimia di salah satu sekolah yaitu SMAN 1 Sungai Tabuk, pada proses pembelajaran yang ada di sekolah itu masih menggunakan cara konvensional. Guru menggunakan metode ceramah pada saat menyampaikan materi sementara siswa hanya duduk untuk mendengarkan penjelasan, sesekali siswa diberikan penugasan dan tanya jawab. Hal4tersebut akan memberikan dampak kurangnya sarana bagi para siswa untuk dapat berkembang secara mandiri dalam penemuan saat berjalan dalam proses berpikirnya.

Untuk siswa, kemampuan dalam berfikir kritis sangat diperlukan dalam proses pembelajaran, dikarenakan dengan pemikiran yang kritis siswa mampu memanfaatkan seluruh kemampuan berfikir mereka dengan maksimal dalam menyelesaikan permasalahan yang ada dalam kehidupan sehari-hari mereka. Kemampuan dalam berfikir kritis juga sangat diperlukan guna meningkatkan keahlian berbahasan dan menganalisis realita dan persoalan yang dihadapi para siswa, sehingga mereka menjadi kreativ dan berkembang dalam proses pembelajaran.

Sanjaya (2014) berpendapat bahwa pikiran baru dikatakan kritis apabila siswa berusaha menganalisa alasan dan persoalan secara teliti, mencari bukti dan penyelesaian yang tepat, serta menciptakan kesimpulan untuk mempercayai dan berbuat sesuatu. Pada saat proses kegiatan pembelajaran di dalam kelas, guru seharusnya menciptakan sebuah pola hubungan dan komunikasi yang lebih tegas pada saat proses pembentuan pengetahuan secara berkelanjutan oleh siswa, sehingga kemampuan berfikir kritis akan tercipta pada diri siswa. Tetapi yang terjadi di lapangan, siswa kebanyakan pasif apabila guru memberikankesempatan untuk mengajukan pertanyaan atau memberikan jawaban dari pertanyaan yang disampainan oleh guru. Dalam setiap mata pelajaran yang diajarkan oleh pengajar, kemampuan berpikir kritis seharusnya diutamakan karena hal itu diajarkan secara khusus sebagai salah satu mata pelajaran, namun dengan kemampuan itulah siswa mampu membangkitkan dan menambah pemahaman, pengertian dan keahlian dari para siswa dalam menyelesaikan persoalan dalam kehidupan sehari-harinya.

Kemampuan berpikir kritis dan materi kimia termasuk dua hal yang saling melengkapi satu sama lain, dikarenakan materi kimia dapat dimengerti melalui proses berpikir kritis dan sebaliknya. Kemampuan berpikir kritis dalam pelaksanaan pengajaran kimia di sekolah cenderung kurang diperhatikan. Suatu proses kegiatan 
belajar mengajar yang didominasi sebagian besar pengajaran konvensional tidak hanya berpengaruh pada berpikir kritis para siswa saja namun juga mempengaruhi pada hasil belajarnya pada salah satu materi kimia yaitu Hidrokarbon. Materi tersebut merupakan materi yang pengaplikasiaanya sangat dekat dengan kehidupan sehari-hari, tetapi masih belum banyak siswa yang sadar akan hal itu dikarenakan belum maksimalnya konsep yang dipahami oleh parasiswa.

Hasil belajar siswa di SMAN 1 Sungai Tabuk pada materi Hidrokarbon tergolong masih kurang dan rendah, hal tersebut dapat diketahui pada ketuntasan ulangan harian materi Hidrokarbon dari tahun ajaran 2015/2016 masih belum sampai kepada KKM yang ditentukan yaitu 75 . Kondisi persoalan pembelajaran tersebut memerlukan upaya agar proses pembelajaran yang ada agar menjadi lebih baik lagi, sehingga hasil belajar dan berpikir kritis siswa juga meningkat. Salah satu upaya yang dimaksud adalah dengan menggunakan pola pembelajaran kooperatif dengan tipe Group Investigation. Pola pembelajaran kooperatif tipe Group Investigation adalah pola pembelajaran yang berkesesuaian denganpaham konstruktivisme, yaitu paham yang memandang bahwa suatu pembelajaran adalah kegiatan yang memungkinkan siswa untuk membangun sendiri pengetahuannya, dan bukanlah memindahkan pengetahuan dari guru ke siswa. (Rusman, 2010). Anas, dkk (2018) mengatakan bahwa pola pembelajaran Kooperatif yaitu Group Investigation wajib melibatkan partisipasi dari tahap penyusunan rencana hingga tahap presentasi yang dilakukan oleh siswa. Pola pembelajaran Kooperatif dengan tipe Group Investigation dapat memperbaiki konsep pemikiran para murid, membantu para murid untuk belajar dengan sendirinya, bekerjasama di dalam kelompok-kelompok dan berani untuk menyampaikan ide-ide mereka. Selain itu pola pembelajaran kooperatif pada tipe Group Investigation siswa dilatih menyelesaikan atau memecahkan suatu bentuk permasalahan.

Dari latar belakang yang telah disampaikan sebelumnya, penulis melakukan sebuah kajian tentang penerapan pola pembelajaran kooperatif pada tipe Group Investigation yang kemudian dikaitkan dengan kemampuan berfikir kritis pada siwa dan hasil belajar siswa pada materi Hidrokarbon di SMAN 1 Sungai Tabuk.

\section{METODE PENELITIAN}

Penelitian ini adalah penelitian quasi experiment yang menggunakan pretestposttest non-equivalent control group design, dengan dua kelas yang terlibat yakni satu sebagai kelas eksperimen dan kelas lain sebagai kelaskontrol. Perlakuan dengan model kooperatif tipe Group Investigation akan diberikan kepada kelas eksperimen, sedangkan kelas kontrol diberi perlakuan dengan model pembelajaran konvensional. Penelititan ini dilaksanakan di SMAN 1 Sungai Tabuk kelas X pada tahun ajaran 2016/2017. Sampel yang digunakan pada penelitian ini diambil dari siswa kelas X3 sebanyak 35 orang yang nantinya disebut kelas eksperimen, yang akan dilakukan kegiatan pembelajaran tentang materi Hidrokarbon dengan pola kooperatif tipe Group Investigation dan siswa kelas X7 sebanyak 36 orang yang disebut dengan kelas kontrol dengan menggunakan model belajar konvensional.

Pemilihan kelas pada penelitian ini dilakukan secara acak. Pengumpulan data yang dilakukan menggunakan teknik tes dengan beberapa tes keterampilan dalam berpikir kritis dan tes pada kemampuan kognitif. Instrumen penelitian diujicobakan untuk mengetahui validitas dan reliabilitasnya. Analisis deskriptif dan analisis inferensial digunakan untuk melakukan analisis data peneliti. Analisis inferensial menggunakan uji-t, tetapi sebelum itu peneliti melakukan uji normalitas kemudian melakukan uji homogenitas. 


\section{HASIL PENELITIAN DAN PEMBAHASAN}

Hasil analisis dari penelitian ini terdiri dari data mengenai hasil tes siswa tentang kemampuan berpikir kritis dan hasil belajarnya. Hasil dari postes penelitian ini terkait tingkat pencapaian dalam kemampuan berpikir kritis siswa yang terdiri atas indikator (1) mengajukan dan menjawab pertanyaan, (2) menentukan tindakan, (3) menganalisis argumen, (4) menalarkan induksi dan mempertimbangkan hasil induksi dapat dilihat pada gambar 1 .

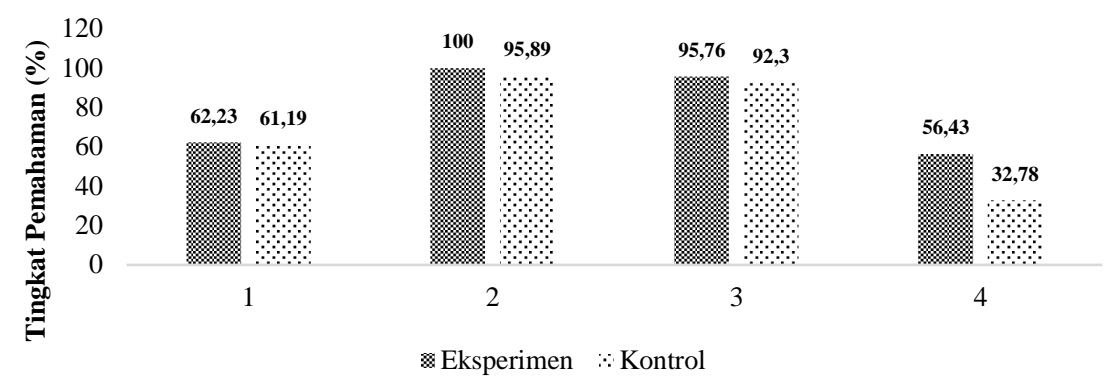

Gambar 1. Persentase pencapaian setiap indikator

Hasil uji-t terhadap rerata pada nilai postes kelas uji coba dan kelas kontrol dapat dilihat pada Tabel 1 dan harga $\mathrm{N}$-gain dapat dilihat pada Tabel 2.

Tabel 1. Hasil uji-t data postes kemampuan berpikir kritis

\begin{tabular}{cccccccc}
\hline Kelas & $\mathbf{N}$ & $\mathbf{D b}$ & $\overline{\mathbf{X}}$ & $\mathbf{S D}^{\wedge} \mathbf{2}$ & thitung & $\mathbf{t}(\mathbf{0 , 0 5})(\mathbf{7 2})$ & Keterangan \\
\hline Eksperimen & 35 & 34 & 74,857 & 29,622 & \multirow{2}{*}{5,045} & \multirow{2}{*}{1,995} & $\begin{array}{c}\text { Ada perbedaan } \\
\text { signifikan }\end{array}$ \\
Kontrol & 36 & 35 & 67,139 & 51,411 & & & \\
\hline
\end{tabular}

Tabel 2. Interpretasi $N$-gain Berpikir Kritis

\begin{tabular}{ccc}
\hline Kelas & Rata-rata $\boldsymbol{N}$-gain & Kategori \\
\hline Eksperimen & 0,73 & Tinggi \\
Kontrol & 0,66 & Sedang \\
\hline
\end{tabular}

Tabel 1 merupakan data yang menunjukan perbedaan signifikan yang terjadi dari hasil pengujian pada kemampuan berpikir kritis di kelas eksperimen dan kelas kontrol pada siswanya. Pada Tabel 2 dapat dijabarkan hasilnya yaitu seberapa besar kenaikan yang terjadi pada kemampuan siswa berpikir kritis pada masing-masing kelas. Artinya, siswa kelas uji coba yang melaksanakan pembelajaran dengan pola belajar kooperatif model Group Investigation ditemukan mengalami peningkatan pada kemampuan cara berpikir kritis siswa yang lebih baik daripada dengan siswa kelas kontrol yang masih menggunakan model konvensional. Dengan kata lain, penerapan pola belajar kooperatif model Group Investigation dapat mempengaruhi kemampuan berpikir kritis pada siswa. Tingkat pemahaman siswa dapat dilihat pada perbandingan dari rata-ratanya hasil belajar kognitif tiap indikator dalam materi hidrokarbon berbeda-beda. Di kelas eksperimen terdapat kualitas pemahaman lebih tinggi jika dibedakan dari kualitas pemahaman yang dimiliki kelas kontrol. Untuk perbandingan rata-rata hasil belajar siswa pada tiap indikator dapat dilihat dari grafik hasil perbandingan persentase jawaban benar antara kelas uji coba dan kelas kontrol yang disajikan pada gambar 2 berikut ini. 


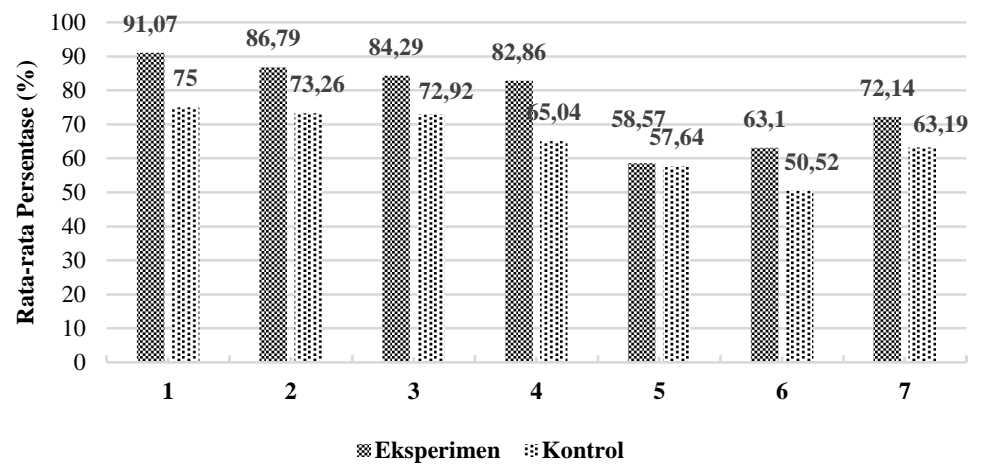

Gambar 2. Tingkat pemahaman siswa kelas uji coba dan kelas kontrol untuk setiap indikator

Keterangan indikator:

$1=$ Deskripsi keistimewaan dari atom karbon pada senyawa

$2=$ Perbedaan atom $\mathrm{C}$ primer, sekunder, tersier, dan kuartener

$3=$ Melakukan pengelompokkan pada senyawa hidrokarbon didasarkan pada kejenuhan ikatan

4 = Menamai senyawa alkana, alkena, alkuna

$5=$ Menentukan Isomer Struktur (Kerangka, posisi, dan fungsi) dan isomer gometri (cis, trans)

6 = Menjelaskan hubungan titik didih senyawa alkana, alkena dan alkuna dan juga massa molekul relatif beserta strukturnya

7 = Menjelaskan dan menulis reaksi sederhana dari senyawa alkana, alkena, dan alkuna

Untuk data hasil uji-t, dan N-gain data postes hasil belajar kognitif disajikan berturut-turut dalam Tabel 3 dan Tabel 4.

Tabel 3. Hasil uji-t data postes hasil belajar kognitif

\begin{tabular}{|c|c|c|c|c|c|c|c|}
\hline Kelas & $\mathbf{N}$ & $\mathrm{Db}$ & $\overline{\mathrm{X}}$ & $\mathrm{SD}^{\wedge} 2$ & thitung & $\mathbf{t}_{(0,05)(72)}$ & Keterangan \\
\hline Eksperimen & 35 & 34 & 75,095 & 10,958 & 3,475 & 1,995 & Ada \\
\hline Kontrol & 36 & 35 & 64,861 & 13,740 & & & $\begin{array}{l}\text { perbedaan } \\
\text { signifikan }\end{array}$ \\
\hline
\end{tabular}

Tabel 4. Interpretasi $N$-gain postes hasil belajar kognitif

\begin{tabular}{ccc}
\hline Kelas & Rata-rata $\boldsymbol{N}$-gain & Kategori \\
\hline Kontrol & 0,53 & Sedang \\
Sedang & 0,71 & Tinggi \\
\hline
\end{tabular}

Tabel 3 menunjukkan bahwa diperoleh perbedaan terjadi secara signifikan antara kelas yang menerapkan cara belajar kooperatif dengan model Group Investigation dan kelas dengan cara belajar konvensional. Sedangkan Tabel 4 menunjukkan seberapa besar perbedaannya. Rata-rata pada $\mathrm{N}$-gain kelas dengan cara belajar kooperatifamenggunakan model Group Investigation memiliki nilai lebih tinggi daripada nilai kelas dengan cara belajar konvensional. $\mathrm{N}$-gain pada kelas8eksperimen berada di kategori yang cukup tinggi, sedangkan pada kelas kontrol berada diidentifikasi pada kategori sedang. 
Hasil tersebut serupa dengan penelitian yang sidah dilakukan oleh Ulum dan Rusly (2015) dimana pola pembelajaran kooperatif model Group Investigation (GI) mampu membuat hasil belajar siswa meningkat, selain itu penelitian yang telah dilakukan Miraningsih dan Azizah (2015) telah mengungkapkan bahwa peningkatan nilai tes yang diperoleh setiap siswa menunjukkan keberhasilan latihan kemampuan siswa berpikir kritis, dan hasil penelitian lain yang dilakukan oleh Wijayanti dan Eko (2014) dengan rerata hasil belajar siswa di kelas eksperimen dengan menggunakan metode pembelajaran koooperatif model Group Investigation meminiliki nilai yang lebih tinggi dibandingkan kelas kontrol.

\section{SIMPULAN}

Berdasarkan penelitian yang telah dilakukan dapat diambil kesimpulan antara lain (1) pada mata pelajaran hidrokarbon, kemampuan soswa berpikir kritis terdapat nilai yang signifikan antara siswa belajar dengan metode pembelajaran kooperatif model Group Investigation dengan siswa yang diperlakukan dengan menggunakan cara konvensional terdapat perbedaan atau berbeda, (2) hasil belajar dari siswa yang talah belajar dengan menggunakan metode pembelajaran kooperatif model Group Investigation dibandingkan siswa belajar dengan menggunakan metode konvensional pada materi hidrokarbon ternyata hasilnya juga terdapat perbedaan.

\section{DAFTAR RUJUKAN}

Anas, Y., Anhar, A., \& Sumarmin, R. (2018). Application of Type Cooperative Learning Models Group Investigation (GI) in Improving Competence Learning Biology Student School. International Journal of Progressive Sciences and Technologies, 6(2), 480-487.

Kemendikbud, D. D. (2015). Panduan Penilaian Untuk Sekolah Menengah Atas. Jakarta: Dikdasmen.

Miraningsih, W. (2015). Penerapan Model Pembelajaran Kooperatif Tipe Group Investigation Untuk Melatihkan Keterampilan Berpikir Kritis Siswa Pada Materi Pokok Asam Basa Kelas XI MIA SMAN 2 Magetan. UNESA Journal Of Chemical Education, 4(2), 281-287.

Rusman, M. M. P. (2010). Mengembangkan Profesionalisme Guru Edisi Kedua. Cet. VI. Jakarta: PT. Raja Grafindo Persada.

Sanjaya, W. (2014). Strategi Pembelajaran Berorientasi Standar Proses Pendidikan. Bandung: Kencana.

Ulum, B. (2015). Penerapan Model Pembelajaran Kooperatif Tipe Group Investigation (GI) Pada Materi Pokok Ikatan Kimia Untuk Melatihkan Keterampilan Berpikir Kritis Siswa Kelas X SMA Widya Darma Surabaya. Unesa Journal Of Chemical Education, 4(2), 156-162.

Wijayanti, A. D., \& Susatyo, E. B. (2014). Penerapan pembelajaran group investigation berbasis inkuiri terbimbing untuk meningkatkan hasil belajar koloid. Jurnal Inovasi Pendidikan Kimia, 8(1), 1300-1308. 